\title{
O CURSO DE PEDAGOGIA DA FE/UNICAMP: AS REFORMULAÇÕES CURRICULARES EM QUESTÃO (1974-1998).
}

\author{
Luciana Cristina Salvatti Coutinho ${ }^{1}$ \\ FE/UNICAMP/ HISTEDBR \\ lucscoutinho@gmail.com
}

\begin{abstract}
RESUMO
Este artigo objetiva analisar as reformulações curriculares do curso de Pedagogia da Faculdade de Educação da Unicamp, ocorridas entre 1974 e 1998. Ao empreender tal tarefa, verificou-se que o projeto implementado a partir de 1998 é fruto de quatro reestruturações efetuadas ao longo de sua história, em confronto com as orientações da política de formação dos profissionais da educação que, por sua vez, foi-se definindo, concomitantemente, à conformação da política educacional em geral, ambas gestadas em função das mudanças na sociedade brasileira.

Palavras-chave: curso de pedagogia; Faculdade de Educação da Unicamp; currículo e história; política educacional; política dos profissionais da educação.
\end{abstract}

\section{PEDAGOGY COURSE AT FE/UNICAMP: CURRICULUM REFORM ANALYSIS (1974-1998)}

\begin{abstract}
This article aims to analyze the curriculum reforms of the Pedagogy course in the Faculty of Education at Unicamp, since its opening in 1974 through to 1998. It was observed that the current curriculum is as a result of four reforms during this period, which were aligned with the training policy of the educational professionals. This policy was defined in parallel with the educational policy, both managed according to the changes in the Brazilian society.
\end{abstract}

Keywords: pedagogy course; Faculty of Education at Unicamp; curriculum and history; educational policy; educational professional policies.

Introdução:

Objetivando reconstruir os aspectos principais e os determinantes fundamentais do currículo do curso de Pedagogia da Faculdade de Educação da Unicamp, ao longo de sua trajetória histórica, um estudo foi desenvolvido durante dois anos, cujos resultados são aqui socializados, sinteticamente. $\mathrm{O}$ trabalho contou com o apoio financeiro do $\mathrm{CNPq}$ por meio de bolsa de Iniciação Científica.

Compreende-se que o currículo do referido curso é fruto de dois movimentos articulados: um interno à instituição, materializado nas disputas, consensos e dissensos que envolvem os profissionais envolvidos no processo; e outro externo, compreendendo a política educacional, em geral e a política de formação dos profissionais da educação, especificamente. Esses dois movimentos que, articulados dialeticamente, englobam diferentes concepções de pedagogia, de pedagogo, de educação, de sociedade, de homem, expressam as mudanças em curso na sociedade historicamente determinada pois, como afirma Saviani(1998): 
(...) o significado da educação está intimamente entrelaçado ao significado da História. E no âmbito da investigação históricoeducativa essa implicação é duplamente reforçada: do ponto de vista do objeto, em razão da determinação histórica que se exerce sobre o fenômeno educativo; e do ponto de vista do enfoque, dado que pesquisar em história da educação é investigar o objeto educação sob a perspectiva histórica. (p.11-12)

O esforço de compreensão histórica de qualquer objeto no âmbito da educação significa entendê-lo como expressão da história da humanidade, da qual se origina e para a qual se estrutura.

Assim é que o curso de Pedagogia foi criado no Brasil em 1939, pelo Decreto-Lei n. 1.190, quando se tinha no comando do país Getúlio Vargas. Nesse momento, buscava-se estimular a "modernização" do país, ou seja, adequá-lo ao desenvolvimento, em curso, do capitalismo. Esta legislação orientou a organização do curso até 1962 quando, através do Parecer 251 e 292, uma nova direção foi dada a ele. Neste momento, estávamos vivendo o período comumente denominado de nacional-desenvolvimentismo. Mais uma vez, buscava-se adaptar a educação às novas exigências do processo produtivo. Em 1969, após o Golpe Militar de 1964, através do Parecer 252, outras diretrizes passaram a servir de fundamento para a organização do curso em questão. A partir desse momento, prevalece, imperiosamente, a lógica de mercado na organização dos cursos de formação profissional, formando cada profissional para a função imediata que ele iria exercer no processo de trabalho.

Esse parecer configura-se como a terceira legislação que imprimiu mudanças na organização do curso de Pedagogia e das funções do Pedagogo. Foram inseridas, nesse momento, as habilitações. Estas tinham como função formar, única e exclusivamente, o profissional direcionado para a função que iria exercer no sistema educacional. Uma base comum era prevista na qual constavam as chamadas disciplinas de fundamentos da educação (história da educação, filosofia da educação, sociologia da educação e psicologia da educação). Após, os estudantes deveriam escolher a habilitação em função do papel que pretendiam assumir na educação: supervisão de ensino, orientação educacional, magistério e administração escolar. Era prevista a formação prática, contudo, somente na área de atuação profissional escolhida pelo futuro pedagogo.

Foi justamente sob a égide dessa orientação de 1969 que o curso de Pedagogia da FE/Unicamp começou a funcionar, em 1974. A estrutura curricular que deu forma e conteúdo à formação do pedagogo, nessa instituição, sofreu, ao longo de sua história, algumas modificações até culminar na organização que passou a ser implementada em 1998.

\section{A criação do curso de Pedagogia da FE/Unicamp:}

A Faculdade de Educação da Universidade Estadual de Campinas - Unicamp - foi criada em 1972, tendo iniciado suas atividades nas dependências do Ciclo Básico, objetivando, em princípio, ministrar as disciplinas pedagógicas dos cursos de licenciatura. Sua organização se deu sob a égide da Lei 5.540/68 (Reforma Universitária), cujos princípios eram a racionalidade, a eficiência e a produtividade do ensino superior, adequando, dessa forma, a Educação à lógica do mercado, própria da sociedade atual.

Após a Reforma Universitária, o curso de Pedagogia sofre uma regulamentação através do Parecer 252/69, aprovado em 11 de abril de 1969 pelo Conselho Federal de Educação, resultando na Resolução n.2/69, no qual são estabelecidos o currículo mínimo e o tempo de duração desse curso, buscando sua adequação às novas orientações da política 
educacional levada a efeito pelo Governo que havia, em 1964, subido ao poder por meio do golpe civil-militar.

Segundo esse Parecer o curso seria dividido em duas partes, sendo uma comum e outra diversificada, composta de matérias distribuídas e combinadas em cinco habilitações, a saber: Orientação Educacional, Administração Escolar, Supervisão Escolar, Inspeção Escolar e Ensino das disciplinas e atividades práticas dos Cursos Normais.

Ainda segundo esse Parecer, o curso de Pedagogia formaria os chamados especialistas da educação e os professores para o Curso Normal que, por sua vez, formariam os professores primários. Seria permitido aos pedagogos que, por falta de professores primários, lecionassem nas séries iniciais de escolarização, afinal "quem pode o mais pode o menos: quem prepara o professor primário tem condições de ser também professor primário" (Parecer CFE 252/69).

O curso de Pedagogia da Faculdade de Educação da Unicamp foi criado em 1973 nos moldes do Parecer supra citado e suas atividades foram iniciadas em $1974 \mathrm{com}$ a finalidade de formar especialistas para a educação tendo sido organizado, assim, em três habilitações: Orientação Educacional, Administração Escolar e Supervisão Escolar.

O curso, nos primeiros anos de sua existência, não oferecia a habilitação para o magistério mas, já em 1976, definia como funções do pedagogo, além de especialista da educação também a de docente de primeiro e segundo graus, estendendo-se aos cursos superiores.

Já em 1977, é acrescida às habilitações existentes a de Magistério da Escola Normal podendo o pedagogo, assim, lecionar as disciplinas e práticas da Escola Normal que se destinavam à formação de professores para a educação infantil e os primeiros anos de escolarização. Afirmava, ainda, que o licenciado em Pedagogia poderia atuar como docente também no primeiro e segundo graus de ensino.

O reconhecimento do curso de Pedagogia da Faculdade de Educação da Unicamp veio através do Decreto ${ }^{\circ} 80.480$ datado de 1977 e previa que o curso ofereceria quatro habilitações: Orientação Educacional, Administração Escolar, Supervisão Escolar e Magistério das Disciplinas Especializadas do Ensino de $2^{\circ}$ Grau (antes denominada de Magistério da Escola Normal).

O currículo, nestes primeiros anos de funcionamento, era organizado em dois blocos: um núcleo comum a todas as habilitações e outro específico a cada habilitação escolhida, sendo permitido o ingresso em uma e no máximo duas habilitações. O núcleo comum de estudos era composto das chamadas disciplinas de fundamentos da educação Sociologia Geral e da Educação, Psicologia da Educação, História da Educação e Filosofia da Educação. O núcleo específico era organizado em disciplinas com os conhecimentos relacionados, em tese, diretamente às funções que os pedagogos exerceriam na educação escolar. O estágio se dava no segundo bloco do curso de acordo com as habilitações escolhidas.

Nesse período, em âmbito nacional, o Conselheiro Valnir Chagas ${ }^{2}$ encaminhou ao Conselho Federal de Educação (CFE) um conjunto de indicações objetivando a reestruturação dos cursos de formação do magistério no Brasil sendo a Indicação n. 70 de 1976 a que propunha a regulamentação do preparo dos especialistas da educação e professores. Nessa Indicação o Conselheiro Chagas defendia a idéia de "formar o especialista no professor" que, diante da impossibilidade de ser feito em cursos de pósgraduação, o seria em habilitações acrescidas aos cursos de licenciatura. Outra Indicação, a n. $67 / 75$ previa a formação de professores para os anos iniciais de escolarização em curso superior não excluindo, onde necessário, o preparo em $2^{\circ}$ grau. Em nenhum momento o 
curso de Pedagogia é eleito como lugar de formação seja de professores, seja de especialistas da educação.

Os educadores interpretaram, com razão, as Indicações do Conselheiro como uma ameaça de extinção do curso de Pedagogia. Além disso, eram contra uma pedagogia tecnicista, fundada nas necessidades imediatas do mercado de trabalho que causava fragmentação dos saberes escolares, a dissociação entre o pensar e o fazer pedagógico e a conseqüente imposição de "pacotes pedagógicos" às escolas, nos quais o papel dos professores se resumiria à "aplicação" dos conhecimentos elaborados por um corpo de especialistas da educação.

Foi nesse contexto que a primeira reformulação curricular do curso de Pedagogia da Faculdade de Educação da Unicamp ocorreu, em 1979.

A reformulação curricular de 1979: permanências

Analisando alguns documentos referentes à primeira reestruturação curricular, tais como as sugestões dos Departamentos e dos estudantes, observou-se alguns temas que estavam em discussão na formação do pedagogo: a definição do educador como agente de transformação social, a necessidade de integração entre teoria e prática no processo de formação do educador, a intrínseca relação entre educação e sociedade e a necessidade de uma política de formação do pedagogo. . $^{3}$

Não houve, no entanto, nenhuma mudança significativa que alterasse as orientações até então seguidas. Essa permanência do projeto do curso em questão operacionalizado por meio do currículo pode ser atribuída a dois fatores: a Resolução CFE n. 2/69 continuava a regulamentar a organização do curso de Pedagogia o que limitava, consideravelmente, as modificações no currículo do referido curso e a própria concepção pedagógica dos educadores envolvidos no processo.

O Parecer n. 252/69 que resultou na resolução n. 2/69 consubstanciou-se na materialização da teoria do capital humano no âmbito educacional por meio da pedagogia tecnicista buscando a racionalização do trabalho pedagógico. Os objetivos a serem perseguidos eram, conforme Saviani (2007b, p. 365-367), atender as demandas de mão-deobra necessárias para as empresas internacionais que se proliferaram no Brasil com a adoção do modelo econômico associado-dependente "associada à meta de elevação geral da produtividade do sistema escolar". Buscando a objetivação do trabalho pedagógico,

(...) a pedagogia tecnicista buscou planejar a educação de modo que a dotasse de uma organização racional capaz de minimizar as interferências subjetivas que pudessem pôr em risco sua eficiência. Para tanto, era mister operacionalizar os objetivos e, pelo menos em certos aspectos, mecanizar o processo. Daí a proliferação de propostas pedagógicas tais como o enfoque sistêmico, o microensino, o telensino, a instrução programada, as máquinas de ensinar etc. Daí também o parcelamento do trabalho pedagógico com a especialização de funções, postulando-se a introdução no sistema de ensino de técnicos dos mais diferentes matizes. Daí, enfim, a padronização do sistema de ensino a partir de esquemas de planejamento previamente formulados aos quais devem se ajustar as diferentes modalidades de disciplinas e práticas pedagógicas (idem, p. 380).

Tanto a organização da Faculdade de Educação da Unicamp quanto o curso de Pedagogia dessa mesma instituição foram criados e organizados sob a égide dessas diretrizes, delimitando o espaço institucional e pedagógico nos quais se davam o ensino e a pesquisa levadas a cabo pelos educadores atuantes na FE/Unicamp. Contrapondo-se a essa 
concepção e as tendências de organização do sistema de ensino brasileiro dela resultante, os educadores buscaram subsídios teóricos que fundamentassem uma resistência ao regime autoritário e os respectivos "pacotes pedagógicos" e pudessem desvelar, ao mesmo tempo, por meio da análise crítica, os determinantes sociais, políticos, econômicos e culturais da educação. Evidência disso é o I Seminário de Educação Brasileira realizado na FE/Unicamp em 1978 para o lançamento do primeiro número da revista "Educação \& Sociedade", fruto da criação do CEDES (Centro de Estudos Educação e Sociedade). O título da revista foi "O Educador precisa ser educado" e do seminário "Função e estrutura da pedagogia na educação brasileira contemporânea" (Coutinho, 2002, p. 71). A centralidade da ação, portanto, nesse momento, era de resistência e crítica apesar de já se evidenciarem alguns apontamentos para a formulação de propostas alternativas às vigentes. Assim, as idéias propositivas, ainda embrionárias, não se configuraram em propostas elaboradas que subsidiassem a reestruturação do curso de pedagogia, de modo geral e se detiveram em aspectos pontuais.

Assim, o currículo a partir de 1979 continuou com as quatro habilitações anteriores e a ser organizado num núcleo comum e outro diversificado, sendo o estágio incluído ao final do curso em função das habilitações escolhidas.

No entanto, uma outra proposta defendida pelo Departamento de Metodologia de Ensino apareceu no debate, nesse momento, em relação ao "lugar e o papel do estágio" no currículo do curso de Pedagogia e que se diferenciava da prática de estágio até então posta, defendendo que o contato dos licenciandos com a realidade educacional deveria se dar desde o início do curso e não somente após as disciplinas de fundamentos. $\mathrm{O}$ argumento que sustentava essa posição destacava a necessidade de articular teoria e prática na formação do pedagogo tendo como ponto de partida a prática pedagógica, sendo imprescindível, desse modo, a inserção do futuro pedagogo nessa prática desde o início do curso através do que foi denominado de "eixo prático do currículo" que compreenderia disciplinas alocadas em todos os semestres do curso cuja finalidade seria a de promover a prática pedagógica do graduando.

Já estava posta uma das questões presentes no currículo do curso de Pedagogia da FE/Unicamp, que viria a ser implementado em 1998, e que gerou, ao longo de sua história, conflitos e negociações.

As discussões em torno da formação dos profissionais da educação não se restringiam ao interior da Faculdade de Educação da Unicamp, ganhando uma projeção nacional. Nessa época (final da década de 1970 e início dos anos 80) estava sendo articulado o fim do Regime Militar, o prenúncio de eleições diretas para a escolha dos dirigentes do país, a mobilização de setores da sociedade buscando a democratização e reformas institucionais, incluindo aí a organização de educadores em torno da formação dos profissionais da educação e da defesa de uma escola pública obrigatória, universal e gratuita para toda a população (XAVIER et al, 1994).

Nesse momento histórico tem início a articulação de um movimento em prol da formação dos educadores, cujo marco é a I Conferência Brasileira de Educação (CBE), ocorrida em 1980, momento significativo de mobilização em torno das políticas educacionais e de formação dos profissionais da educação. Em decorrência dessa mobilização foi criado o Comitê Nacional Pró-Reformulação dos Cursos de Formação de Educadores numa atitude de resistência às ameaças do Conselho Federal de Educação de extinção do curso de Pedagogia.

O Comitê tinha, no início, como objetivos gerais, a mobilização e a conscientização "da importância das políticas educacionais e da valorização dos profissionais da educação" 
(BRZEZINSKI, 1996, p.95), e a redefinição curricular do curso de Pedagogia, como objetivo específico, em busca da identidade do referido curso e do pedagogo.

No interior do movimento para a Formação do Educador, as questões que estavam em pauta diziam respeito, em suma, ao próprio conceito de escola entendida como instituição social, o papel da educação e sua relação com a sociedade, evidenciando a dimensão política do ato educativo e a função do educador entendido como agente transformador, concepção apoiada nas teorias críticas da educação.

As teorias críticas da educação contrapõem-se às teorias não críticas que concebem a sociedade como harmônica no sentido de buscar a integração dos seus membros sem alterar, contudo, as bases de organização da sociedade. A educação aparece, nesta perspectiva, como neutra e, portanto, como o fenômeno capaz de promover essa integração. Nesse sentido, a relação da educação com a sociedade é de autonomia e mais, a constituição e equalização social está subordinada à educação.

As teorias críticas podem ser subdivididas em dois grupos: as crítico-reprodutivistas e as críticas não reprodutivistas. As primeiras avançam em relação as não críticas ao evidenciarem a determinação social da educação, sendo esta vista numa perspectiva de total subordinação em relação à sociedade. Já as teorias críticas não reprodutivistas consideram o importante avanço das teorias crítico-reprodutivistas mas buscam, na realidade concreta, elementos que possibilitem a ação efetiva dos educadores na transformação da educação e da sociedade. A relação entre educação e sociedade, desse modo, é dialética, ao mesmo tempo determinam e transformam uma a outra (SAVIANI, 2007).

Nas perspectivas críticas da educação, o ato educativo configura-se como um ato político no sentido de poder legitimar ou negar determinados conhecimentos escolarizados que são selecionados tendo em vista determinados "modelos" ideológicos e econômicos na sociedade. O educador, desse modo, por meio do seu trabalho pedagógico, ensina muito mais que conteúdos escolares ensina, também, valores, normas e dependendo do lado de quem se coloca nesse processo de trabalho pode colaborar para manter o status quo ou para transformar a realidade sócio-política e econômica.

Diante dessas questões, o Movimento dos Educadores delineia diretrizes que são, basicamente: formar o educador no professor (prenunciando a posição do movimento para o fim das habilitações); valorização da escola pública; priorização da escola básica e superação da dicotomia entre teoria e prática na formação do pedagogo.

Em 1981, o Ministério da Educação e Cultura (MEC) evidenciou sua posição de direcionar o processo de reforma do curso de Pedagogia ao elaborar um documento "gerador" de discussões e reformulações cujo título era "Estudo preliminar sobre reformulação dos cursos de formação de recursos humanos para a educação", e enviá-lo às Faculdades e Institutos de Educação, apontando as deficiências dos cursos de formação de educadores e a necessidade de propostas reformuladoras (MEC, 1981).

Surge, assim, uma parceria entre o movimento dos educadores e o MEC, materializada em sete seminários ocorridos entre agosto e outubro de 1981, buscando discutir e apresentar propostas de reformulação dos cursos de formação de educadores, elencando os princípios que subsidiariam a política de formação de professores.

Os resultados desses seminários foram organizados num Documento Síntese no qual foram registradas as propostas de mudança curricular dos cursos de formação de profissionais da educação, nas quais o currículo seria organizado em duas partes: uma comum e outra diversificada, possibilitando uma sólida base de formação tanto geral quanto pedagógica. 
A parte comum compreenderia o período de 2 a 4 semestres, abrangendo os conteúdos das Ciências da Educação e suas relações com as demais áreas do conhecimento tendo como foco a Educação e sua relação com a sociedade.

Na parte diversificada do currículo, quatro eram as proposições apresentadas: uma que defendia a formação exclusiva do docente; outra que propunha a formação do pedagogo generalista sem privilegiar a formação do professor. Uma terceira modalidade que surgiu dispunha a organização do curso em dois blocos. O primeiro se destinava à formação docente, abrangendo a formação de professores para as primeiras quatro séries do primeiro grau, para o ensino especial, para a alfabetização de adultos e para o magistério de segundo grau. $\mathrm{O}$ segundo bloco se referia à formação de especialistas nãodocentes, envolvendo tanto as habilitações tradicionais (Orientação, Supervisão, Administração, Inspeção e Planejamento) como outras que viessem a ser criadas; e a quarta proposta defendia a formação dos professores em suas diferentes especialidades e a formação dos especialistas da educação em cursos de pós-graduação, com exigência de experiência de magistério. É interessante destacar que em todas as propostas apresentadas nos seminários, o estágio surgiu como ponto de concordância no sentido de adequá-lo à necessidade de superar a dicotomia entre a teoria e a prática no processo de formação dos profissionais da educação (BRZEZINSKI, 1996, p.148).

O Comitê de Educadores, a partir de 1983, passou a se organizar numa Comissão Nacional de Reformulação dos Cursos de Formação de Educadores (CONARCFE), promovendo o I Encontro Nacional do Movimento, em Belo Horizonte, a fim de iniciar um processo de avaliação das tendências de reformulações levadas a cabo pelas Instituições de Ensino Superior.

Os temas em debate estavam presentes tanto na Comissão dos Educadores quanto na Faculdade de Educação da Unicamp, já que alguns membros do movimento eram também docentes da instituição em questão.

O currículo de 1984: mudanças na Habilitação Magistério

No período de 1983/84, ocorreu na Faculdade de Educação da Unicamp uma discussão suscitada pelos debates do I Encontro Nacional da CONARCFE, com o objetivo de provocar mudanças na Habilitação Magistério do curso de Pedagogia da referida instituição. A proposta de reformulação, encabeçada pelo Departamento de Metodologia de Ensino (DEME), baseada em algumas avaliações do curso da FE/Unicamp que apontavam como problema central a necessidade do trabalho docente constituir-se como base de formação do pedagogo, introduziu as seguintes modificações:

1. a introdução das cinco didáticas ${ }^{4}$ específicas como obrigatórias para os alunos da Habilitação Magistério;

2. a introdução de Metodologia, Ciência e Sociedade e da Didática Integrada (disciplina oferecida somente uma vez);

3. ampliação da carga horária de metodologia de Ensino de $1^{\circ}$ grau de 4 hs para 8 hs (4 teóricas e 4 práticas);

4. ampliação do número de horas do estágio de 6 horas semanais para 12 horas semanais $(180 \mathrm{hs} / \mathrm{semestrais}=360 \mathrm{hs} /$ anuais $)$, incluídas na carga horária do aluno (FREITAS, 1993, p.101).

As mudanças levadas a efeito, nesse período, limitaram-se a introduzir algumas alterações exclusivamente na Habilitação Magistério, não provocando, portanto, nenhuma modificação significativa quanto à organização do curso como um todo. Mesmo assim, merecem destaque pelo fato de já apontarem a importância que passaria a ser dada, 
paulatinamente, à formação prática do pedagogo, limitando-se, nesse momento, à função docente e estendendo-se, como se evidencia no currículo atual do curso, à formação do pedagogo de modo geral.

\section{Novas tentativas de reformulação}

A partir de 1986, na Unicamp, teve início um processo de avaliação dos cursos de graduação e o incentivo à implantação dos cursos noturnos. Esse processo englobou todos os Institutos e Faculdades da Universidade Estadual de Campinas. A necessidade evidenciada pela Universidade de criar os cursos noturnos se impôs após a promulgação da Constituição, que obrigava as universidades a oferecer, no período noturno, pelo menos um terço do total das vagas.

De acordo com o Reitor da Unicamp, em ofício enviado à Faculdade de Educação, a organização do curso noturno, além de se constituir numa prioridade, naquele momento, demandava criatividade e ideias inovadoras já que, segundo ele, a vida acadêmica à noite possuía especificidades que deveriam ser levadas em conta, não cabendo, simplesmente, a duplicação do curso oferecido no período diurno.

Em função desse processo de avaliação dos Cursos de Graduação, volta à tona a discussão referente à reformulação do curso de Pedagogia em meados de 1987, mas, dessa vez como uma iniciativa do Centro Acadêmico de Pedagogia a partir de um estudo realizado acerca dos problemas enfrentados durante o curso. Esse levantamento deflagrou a instauração de uma Comissão para reformulação do curso, em 1988.

De acordo com FREITAS (1989), após o Centro Acadêmico enfrentar algumas dificuldades para encaminhar propostas de reformulação, a Coordenação do curso de Pedagogia da FE/Unicamp assumiu esse papel e enviou à comunidade acadêmica uma proposta de reestruturação curricular do referido curso, contendo vários dados referentes sua organização, número de alunos, distribuição destes pelas diferentes habilitações, num diagnóstico panorâmico do curso. $\mathrm{O}$ texto da proposta também continha várias idéias que, segundo o próprio documento, estavam em consonância com os princípios oriundos do Movimento dos Educadores dentre os quais, destaca-se: a relação teoria/prática como núcleo integrador da formação do educador e a docência como base da identidade do profissional da educação. Constava também do documento a proposta de criação do curso noturno.

Ao ser apresentada à comunidade acadêmica, a proposta de reformulação curricular encontrou muita resistência por parte dos docentes da Faculdade de Educação e o processo de reestruturação do curso foi suspenso. Os dissensos giravam em torno, sobretudo, da concepção do profissional formado no curso de Pedagogia, sendo que uns entendiam que deveria ser organizado para formar professores, enquanto que outros pregavam que a Faculdade de Educação e o curso de Pedagogia não poderiam ter como foco de trabalho a formação de professores, mas sim a pesquisa acerca da educação. Outro dissenso que merece destaque pois mobilizou vários dos departamentos da Faculdade de Educação, diz respeito ao eixo prático do currículo materializado em disciplinas denominadas de "Pesquisa e Prática Pedagógica" além do estágio supervisionado, garantindo, segundo a proposta, a superação da dicotomia entre teoria e prática no processo de formação do pedagogo.

Nesse mesmo período, em âmbito nacional, a Comissão Nacional dos Educadores buscava se reorganizar a fim de obter maior prestígio no meio acadêmico e, com isso, mobilizar mais forças na tentativa de influir nas decisões políticas acerca da educação e dos profissionais da educação, principalmente na elaboração da nova Lei de Diretrizes e Bases da Educação Nacional (1996). 
Com esse intuito, no V Encontro Nacional da Comissão realizado em 1990, a CONARCFE foi transformada em Associação Nacional pela Formação dos Profissionais da Educação (ANFOPE). Com características mais formais e permanentes, a Associação redimensiona seus objetivos com a promoção de estudos acerca da formação dos educadores que serviriam como referência para as Instituições de Ensino Superior subsidiarem as reformulações dos seus cursos.

Desde o início do Movimento dos educadores, em 1980, algumas idéias foram se delineando, culminando, na década de 1990, em dois temas centrais: a organização de princípios gerais norteadores, destacando a docência como base da identidade dos profissionais da educação e a articulação teoria/prática como núcleo integrador da formação; e uma base comum nacional ${ }^{5}$, que garantiriam certa organicidade aos cursos e uma identidade comum aos profissionais da educação e, ao mesmo tempo, respeitariam as especificidades de cada instituição.

No interior da Faculdade de Educação/Unicamp, em 1989, nova tentativa de reestruturação não logrou êxito pois era prioritário, naquele momento, a fim de cumprir a obrigatoriedade instituída pela nova Constituição, criar o curso noturno.

Criação do curso noturno: caminho para a reformulação de 1992

A orientação da Reitoria, em 1986, solicitando a apresentação de uma proposta inovadora para o curso noturno e o prazo estipulado pela Comissão Central de Graduação para a implantação do curso noturno até 1991 foram fatores que colaboraram para que a organização do curso de Pedagogia se desse nos moldes do documento/proposta denominado "Elementos para a Reformulação do Curso de Pedagogia da Faculdade de Educação da Unicamp (1987)" de autoria do Prof. Dr. Luiz Carlos de Freitas, docente da Faculdade de Educação e membro efetivo do movimento dos educadores e que havia, pouco tempo antes, sido criticada e rejeitada por parte significativa da comunidade acadêmica. Guardadas as divergências suscitadas pela proposta era, naquele momento, uma proposta pronta e fundamentada para a organização do curso de Pedagogia tendo sido aprovada na Congregação.

Desse modo, o curso de Pedagogia da FE/Unicamp, no período noturno, ficou organizado em habilitações para o magistério do Pré-Escolar, das Séries Iniciais do primeiro grau, das Matérias Pedagógicas do segundo grau e para as classes de alfabetização, de acordo com o princípio de que a base de formação do pedagogo seria a docência. Além disso, a disciplina "Pesquisa e Prática Pedagógica" foi introduzida no currículo constando nos três primeiros semestres, possibilitando ao aluno, segundo o projeto do curso, o contato com a realidade educacional desde o início do curso e a articulação entre teoria e prática no processo de formação. No curso noturno evidenciou-se, na FE/Unicamp, ainda mais fortemente, a importância da formação prática do pedagogo com a centralidade da formação do pedagogo na docência e com a ampliação de disciplinas centradas na prática pedagógica. A importância da formação prática parece guardar uma relação direta com a centralidade da docência na formação do pedagogo.

Durante os anos de 1991 e 1992, a Comissão instaurada para implementar o curso noturno continuou suas atividades mas focando, a partir daquele momento, a reformulação do curso diurno, objetivo alcançado em 1992.

Assim, a estrutura curricular do curso diurno de Pedagogia da FE/Unicamp, a partir de 1993, incorporando a docência como base de formação do pedagogo, tornou obrigatória a Habilitação Magistério das Séries Iniciais de Escolarização, podendo o estudante optar por mais uma habilitação dentre outras quatro oferecidas pela instituição, quais sejam: Administração Escolar, Supervisão Escolar, Magistério para educação pré-escolar e 
Educação especial. A inclusão das disciplinas "Pesquisa e Prática Pedagógica I, II e III" também foi outra alteração significativa na organização do curso que, junto com outras disciplinas (Didática, Metodologia do I Grau, Estágios Supervisionados) passaram a compor o "eixo prático do currículo".

A criação do curso noturno, portanto, possibilitou a reorganização curricular do curso diurno tendo como fundamentos a inserção de dois princípios fundamentais defendidos pelo Movimento dos Educadores para a formação dos profissionais da educação: a docência como base da formação e a articulação teoria/prática no processo de formação profissional.

A reformulação curricular de 1998: fim das habilitações

Outra reestruturação curricular do curso de Pedagogia da FE/Unicamp ocorreu nos anos de 1996 e 1997, tendo sua implementação se dado a partir de 1998. Esse processo teve início a partir de uma iniciativa da então coordenadora do curso de Pedagogia, Profa. Dra. Helena Costa Lopes de Freitas, docente do Departamento de Metodologia de Ensino que, além de elaborar trabalhos na temática da formação de profissionais da educação também é membro do Movimento de Educadores, tendo sido presidente da ANFOPE de 1996 a 2000, o que lhe forneceu subsídios para coordenar o processo.

Assim, a Coordenação do curso de Pedagogia incluiu na pauta da Congregação da Faculdade de Educação, em junho de 1996, a criação de uma Comissão Ampliada que teria como objetivo reformular o curso de Pedagogia, sendo aprovada por unanimidade.

A fim de promover uma discussão mais ampla e situar o curso da Unicamp no contexto de mudanças que se iniciaram na década de 90 nos demais cursos de Pedagogia das Universidades Públicas, foi organizado, em setembro de 1996, um seminário intitulado "Curso de Pedagogia: experiências em construção".

Foram apresentadas experiências que estavam em desenvolvimento na Universidade Federal Fluminense, na Universidade Federal de Mato Grosso e na Universidade Federal de Minas Gerais. Os aspectos fundamentais dos currículos apresentados eram: a docência como base da formação do pedagogo e a extinção das habilitações e a organização curricular a partir de eixos curriculares sendo um deles a necessidade de vinculação entre teoria e prática no processo de formação do pedagogo, consubstanciada através de disciplinas específicas. Outros eixos curriculares elencados eram: sólida formação teórica, compromisso social, trabalho interdisciplinar, gestão democrática.

A Comissão Ampliada, baseada nas experiências em curso apresentadas no seminário e apoiando-se nos princípios norteadores disseminados pela ANFOPE, elaborou a primeira versão do currículo apresentada à comunidade acadêmica, para discussão, no início de 1997.

O norte do trabalho da Comissão Ampliada era a superação da fragmentação do curso de Pedagogia causada, segundo a proposta, pelas habilitações e criar condições para que o pedagogo tivesse a compreensão do trabalho pedagógico como um todo (escolar e não-escolar). Assim, a proposta curricular apresentada não estava mais organizada em função das habilitações que seriam extintas.

A extinção das habilitações não foi uma questão muito conflituosa entre os docentes, com exceção de alguns que faziam parte do Departamento de Administração e Supervisão Escolar (DASE) que se posicionaram contrários a essa iniciativa, defendendo que o pedagogo formado sem habilitação específica para atuar em áreas administrativas na organização escolar, estaria em desvantagem no mercado de trabalho que demandava um profissional com formação especializada. A posição do DASE, portanto, foi a de que a 
proposta deveria ser mais discutida antes de sua aprovação já que o professor, no exercício de sua profissão, tinha possibilidade de assumir cargos administrativos sendo necessário, assim, que sua formação abrangesse a administração escolar.

Outra questão polêmica nessa reformulação curricular foi o lugar e o papel da prática no processo de formação do pedagogo, questão essa que acompanha a história do referido curso.

Segundo a primeira versão da proposta curricular, seria mantido o eixo prático do currículo composto por disciplinas que teriam o papel de introduzir os estudantes na realidade educacional desde o início do curso. Essa idéia parte do pressuposto de que o professor é um profissional que atua e se forma, continuamente, no contexto de sua prática pedagógica que, por encontrar-se em constante mudança, requer o enfrentamento dessas mudanças através de um processo de ação e reflexão contínuo sobre sua própria prática pedagógica (GORESTEIN et al, 2002). Nessa perspectiva, o trabalho pedagógico tende a ser reduzido ao seu aspecto prático, sendo os conhecimentos produzidos historicamente acerca da educação, entendidos somente como instrumentos de análise da prática, não lhes cabendo a tarefa de orientação do processo de ensino-aprendizagem. É visível a primazia dessa concepção na orientação dos estágios supervisionados cujo trabalho é centrado na análise da prática pedagógica, não sendo considerado o processo de trabalho como um todo, incluindo seu planejamento, execução e avaliação, organizado de acordo com a concepção que se tem de educação e a relação desta com a sociedade.

No entanto, uma outra concepção é defendida, principalmente, pelo Departamento de Filosofia e História da Educação (DEFHE). Segundo os docentes do DEFHE, os licenciandos deveriam ser instrumentalizados teoricamente para compreender e interpretar a organização da escola, do sistema educacional e sua relação com a sociedade mais ampla tendo, assim, condições reais para planejar uma ação com o intuito de interferir na realidade educacional, ou seja, uma ação intencionalmente planejada buscando atingir determinados objetivos educacionais. Dessa perspectiva, defendiam que a formação do educador não poderia ser centrada na prática pedagógica que ocorre no interior das escolas, mas que esta deveria ser tomada como ponto de partida e de chegada da organização do trabalho pedagógico, numa relação de dependência e determinação mútuas entre a teoria e a prática pedagógica, elementos distintos mas indissociáveis do processo de ensinoaprendizagem (SAVIANI, 2007).

O resultado desse embate de concepções acerca da prática na formação do pedagogo foi a supressão, após a apresentação para discussão da primeira versão curricular, do termo "Prática" das disciplinas denominadas "Pesquisa e Prática Pedagógica" que foram reduzidas a duas (eram três) na organização curricular do curso.

Segundo a proposta da Comissão Ampliada, as disciplinas do "eixo prático" do currículo deveriam ser de responsabilidade de uma Comissão e não mais dos Departamentos, o que também causou discussões e pronunciamentos contrários dos departamentos, sendo esse item suprimido do projeto curricular aprovado pela Congregação da FE/Unicamp.

Além disso, o Departamento de Ciências Sociais aplicadas a Educação (DECISAE), atualmente denominado de DECISE (Departamento de Ciências Sociais na Educação), manifestou-se acerca da concepção de formação continuada presente na proposta considerando-a idealizadora, entendendo que não se trata de um processo compulsório, mas definido pelo mercado de trabalho e pelo governo, por meio dos sistemas de avaliação.

Após as modificações oriundas das críticas e sugestões dos docentes da Faculdade de Educação da Unicamp, o currículo implementado em 1998 apresentou algumas "marcas": as disciplinas "Pesquisa e Prática Pedagógica I, II e III" que comporiam, junto 
com outras, o "eixo prático" do currículo, sofreram duas alterações, passando a ser denominadas somente de "Pesquisa Pedagógica" e sendo reduzida a duas; a Prática de Ensino de I grau passou a ser Prática de Ensino nas séries iniciais do Ensino Fundamental em função de mudanças na denominação dos níveis da escolarização básica, ou seja, o que era o Ensino de I grau passou a ser chamado de Ensino Fundamental e o Ensino de II grau denominou-se de Ensino Médio.

O currículo foi organizado enfatizando o magistério das séries iniciais de escolarização ( $1^{\mathrm{a}}$ a $4^{\mathrm{a}}$ séries), apesar de considerar como funções do pedagogo a docência em educação infantil e educação especial. Também foram privilegiadas algumas disciplinas que compunham as habilitações de Administração e Supervisão Escolar, entendendo que forneceriam uma visão global da organização escolar e, por fim, foram mantidas as chamadas disciplinas de fundamentos da educação, quais sejam: História da Educação, Sociologia Geral e da Educação, Filosofia da Educação e Psicologia da Educação.

É explicitado no projeto pedagógico do curso que o pedagogo pode atuar em várias áreas da educação escolar e não escolar sendo o estágio efetuado em duas áreas específicas: nos primeiros anos do ensino fundamental e administração escolar.

No ano de 2008, após a promulgação das Diretrizes Curriculares para o Curso de Pedagogia, instituída pelo Conselho Nacional de Educação em 2006, novas mudanças na estrutura curricular do curso em questão foram efetuadas. Caberia, agora, verificar o caminho percorrido de 1998 até os dias atuais a fim compreender como se dá, atualmente, na FE/Unicamp, a formação dos pedagogos. Essa tarefa será objeto de outro artigo que pretende-se redigir.

\section{Considerações Finais}

O caminho percorrido procurou evidenciar que o currículo do curso de Pedagogia da Faculdade de Educação da Universidade Estadual de Campinas, implementado a partir de 1998, foi resultado de um processo de debates e negociações ocorridos nos anos de 1996 e 1997 e também das modificações que foram sendo implementadas ao longo de sua história.

Essa reformulação curricular do referido curso não se restringiu à instituição em questão estendendo-se aos cursos de Pedagogia das Universidades Públicas a partir de 1990 que, mesmo com características específicas, apresentaram orientações comuns. Assim, o currículo em questão também foi fruto de uma tendência nacional de formação do pedagogo.

Esse quadro de mudanças vem sendo articulado com as orientações da política de formação dos profissionais da educação principalmente a partir da década de $80 \mathrm{com}$ a mobilização dos educadores em torno dessa questão, buscando influir na conformação da legislação que regulamenta os cursos de formação dos profissionais da educação, em geral, e dos pedagogos, em particular. A estratégia dos educadores de irem para o embate, organizando-se, promovendo estudos, elaborando propostas, abriu caminhos para que experiências de organização de cursos, objetivando formar profissionais que, por meio do seu trabalho pedagógico, possibilitem a formação de seres humanos capazes de buscar as condições de superação da sociedade atual, fossem possíveis.

No interior das instituições de ensino superior, esse embate também se faz presente, podendo ser percebido nos momentos de reestruturações curriculares, onde o confronto de concepções divergentes surge e gera uma situação de conflito e a necessidade de negociação. 
O projeto pedagógico de um curso, materializado no currículo, é fruto, portanto, de um embate de concepções no interior das instituições de ensino, sendo limitado, no entanto, pelas regulamentações postas aos cursos definidas pela política educacional. Estas, por sua vez, são expressões do confronto de concepções no âmbito da sociedade acerca dos processos educativos. Essas concepções divergentes originam-se no embate entre classes e frações de classes que expressam e defendem interesses divergentes acerca da educação e de sua relação com a sociedade. Não basta, desse modo, travar somente um embate interno buscando efetuar mudanças efetivas na configuração dos cursos, faz-se necessário que a luta extrapole os limites das instituições e se busque formas de participação na conformação das políticas educacionais e de mecanismos outros que possam alavancar mudanças na própria estrutura social.

Assim, para além das diferenças que separam, no interior das instituições, as posições dos docentes, discentes e demais membros de uma comunidade acadêmica, é imprescindível buscar os pontos em comum que possam propiciar a união dos educadores e de todos aqueles interessados em lutar por uma educação gratuita, universal, laica e de qualidade para todos, objetivo ainda não alcançado em nossos dias.

\section{Referências}

BRASIL. Conselho Federal de Educação. Parecer n. 252/69.

BRASIL. Conselho Nacional de Educação. Resolução CNE/CP 1/2006 - Institui Diretrizes Curriculares Nacionais para o Curso de Graduação em Pedagogia, licenciatura.

BRASILIA. MEC. Estudo preliminar sobre reformulação dos cursos de formação de recursos humanos para a educação. Brasília, 1981.

BRZEZINSKI, Iria. Pedagogia, pedagogos e formação de professores: busca $e$ movimento. Campinas, SP: Papirus, 1996.

COUTINHO, Luciana C. S. Curso de Pedagogia da Unicamp: processo de reformulação curricular. Trabalho de Conclusão de Curso (TCC). Campinas, SP, s.n., 2002.

FREITAS, Helena Costa Lopes de. O Trabalho como princípio articulador da Teoria/Prática: uma análise da prática de ensino e estágio supervisionados na habilitação magistério do curso de Pedagogia da FE/Unicamp. Universidade Estadual de Campinas: Faculdade de Educação, 1993.

FREITAS, L C. de. Elementos para a reformulação do Curso de Pedagogia da Faculdade de Educação da Unicamp. FE/UNICAMP, Coordenação de Pedagogia, 1989.

GORESTEIN, M. R. (et al). Formação de professores e Gestão Escolar. In ROSSI, V.L.S. de. Rédeas (in)Visíveis da Gestão do Trabalho Pedagógico: coletânea de textos dos alunos do curso de Pedagogia da FE/Unicamp.Campinas, SP: Graf. FE, 2002. MARIN, Alda J. \& GIOVANNI, Luciana M. Expressão escrita de concluintes de curso universitário para formar professores. In SAVIANI, D. \& MARIN, Alda J.(org). Cadernos de Pesquisa, v. 37, n. 130. São Paulo: Fundação Carlos Chagas, jan/abr 2007,

Pronunciamento conjunto das entidades da área da educação em relação às Diretrizes Curriculares Nacionais para o Curso de Graduação em Pedagogia. In Educação \& Sociedade, v. 27, n. 97. Campinas, SP: CEDES, set/dez 2006, p. 1361-1363.

SAVIANI, Dermeval. A nova lei da educação: trajetória, limites e perspectivas. 3 ed. Campinas, SP: Autores Associados, 1997. 
SAVIANI, D; LOMBARDI, J. C; SANFELICE, J. L. História e História da educação: o debate teóricometodológico atual. Campinas, SP: Autores Associados: HISTEDBR, 1998. SAVIANI, Dermeval. Educação: do senso comum à consciência filosófica. 13 ed. São Paulo: Autores Associados, 2000.

SAVIANI, Dermeval (et al). O legado educacional do século XX no Brasil. Campinas, SP: Autores Associados, 2004.

SAVIANI, Dermeval. Escola e democracia: teorias da educação, curvatura da vara, onze teses sobre a educação política. 39a ed. Campinas, SP: Autores Associados, 2007.

SAVIANI, Dermeval. Pedagogia: o espaço da Educação na Universidade. In Cadernos de Pesquisa, v. 37, n.130. São Paulo: Fundação Carlos Chagas, jan/abr 2007a.

SAVIANI, Dermeval. História das Ideias Pedagógicas no Brasil. Campinas, SP: Autores Associados, 2007b.

TANURI, Leonor Maria. História da formação de professores. In Revista Brasileira de Educação, n. 14, 2000, p. 61 - 88.

XAVIER, Maria Elizabete S. Prado (et al). História da Educação: a escola no Brasil.São Paulo: FTD, 1994.

Notas

\footnotetext{
${ }^{1}$ Doutora em História da Educação pela Faculdade de Educação da UNICAMP.

${ }^{2}$ Autor do Parecer n.252/69 incorporado à Resolução n.2/69 que regulamentou o curso de Pedagogia até a nova Lei de Diretrizes e Bases da Educação Nacional de 1996.

${ }^{3}$ Cf. Posições documentadas dos departamentos: DEME - Departamento de Metodologia de Ensino, DEFHE - Departamento de Filosofia e História da Educação, DASE - Departamento de Administração e Supervisão Educacional (atualmente DEPASE - Departamento de Políticas, Administração e Sistemas Educacionais) e DSE - Departamento de Sociologia da Educação (que passa, posteriormente, a ser o DECISAE Departamento de Ciências Sociais Aplicadas à Educação e atualmente é denominado de DECISE Departamento de Ciências Sociais na Educação) e Corpo Discente da FE/Unicamp, 1979.

${ }^{4}$ Alfabetização, Matemática, História, Geografia e Ciências.

${ }^{5}$ Sobre a base comum nacional: "do ponto de vista técnico trata-se de elencar as grandes áreas temáticas ou eixos da formação do educador. Do ponto de vista político trata-se de um instrumento de luta contra a degradação da formação do profissional da educação". ANFOPE. VI Encontro Nacional.Documento Final, 1992:8-9.
}

Recebido em maio/2012

Aprovado em setembro/2012 
